\section{EDUCAÇÃO}

V.10 • N.2 • Número Temático - 2020

ISSN Digital: 2316-3828

ISSN Impresso: 2316-333X

DOI: 10.17564/2316-3828.2020v10n2p37-49
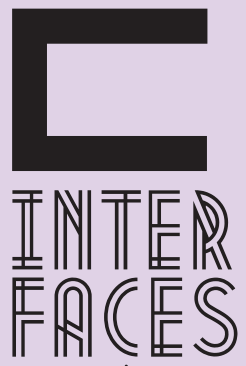

CIENTÍFICAS

\title{
LETRAMENTO DIGITAL CRÍTICO: A VOZ DO HIPERLEITOR NAS NARRATIVAS ORAIS APLICADAS AO ROLE PLAY GAMEDIGITAL
}

CRITICAL DIGITAL LITERACY: HYPER-READER 'S VOICE IN THE ORAL NARRATIVES APPLIED TO THE DIGITAL ROLE PLAY GAME

ALFABETIZACIÓN DIGITAL CRITIICA: LA VOZDEL HIPERLECTOR EN LAS NARRATIVAS ORALES APLICADAS AL ROLE PLAY GAMEDIGITAL

Geisa Araújo Dias ${ }^{1}$ Úrsula Cunha Anecleto ${ }^{2}$

\section{RESUMO}

Este artigo, recorte de dissertação de mestrado ainda em andamento, problematiza sobre a formação do hiperleitor na perspectiva do Letramento Digital Crítico e tem como foco a retextualização de narrativas orais de moradores do campo do município de Monte Santo (BA), transformando-as em narrativas hipertextuais. Nesse ínterim, discutem-se efeitos que a leitura desses textos multiletrados apresenta na formação de hiperleitores. Metodologicamente, sustenta-se na abordagem qualitativa, na pesquisa participante e na análise de conteúdo. Como produto, pretende-se a construção do jogo Role Play Game Digital (RPG) para a divulgação dos textos retextualizados. Como resultado da pesquisa, projeta-se que as narrativas hipertextuais irão promover uma experiência de intercâmbio de memórias entre comunidade e alunos, oportunizando sua preservação por uma rede mais ampla, a partir de meios digitais.

\section{PALAVRAS-CHAVE}

Letramento Digital Crítico. Hiperleitor. Narrativas Orais. Game Digital/RPG. 


\section{ABSTRACT}

This article, part of a master's dissertation still in progress, discusses the hyper reader formation on the critical digital literacy perspectivity, and it has as a mean objective the oral narratives retextualizations of the county dwellers on the Monte Santo's (BA) city, turning it into hypertextual narratives. In this essay, the effects that the reading of these non-linear texts shows in the hyper-readers formation. The methodology of this research is based on the qualitative approach, the study participating and in the content analysis. As a final product, this essay intends the use of the Role Play Game (RPG) as a tool in order to spread the retextualized texts. As the main result of the research, it's expected that the hypertextual narratives will promote an exchange memory experience between community and students, allowing its preservation by a wider network: the digital media.

\section{KEYWORDS}

Critical digital Literacy; Hyper-reader; Oral Narratives; Digital Role Play Game (RPG).

\section{RESUMEN}

Este artículo, que forma parte de la disertación de maestría aún em curso, debate sobre la formación del hiperlector en la perspectiva de la Literacidad Digital Crítica y se foca en la retextualización de narrativas orales de habitantes rurales del municipio de Monte Santo (BA), transformando tales narrativas en hipertextuais. Entretanto, se discute efectos que la lectura de estos textos multiletrados presenta en la formación de hiperlectores. Metodológicamente, se apoya en un acercamiento cualitativo, en la investigación activa y en análisis de contenidos. Como producto, se pretende la construcción del Role Play Game Digital (RPG) para la divulgación de los textos retextualizados. Como resultado de la investigación, se proyecta que las narrativas hipertextuales propicien una experiencia de intercambio de memorias entre la comunidad y los estudiantes, beneficiando su preservación oportuna a través de una red más amplia, a partir de medios digitales.

\section{PALABRAS CLAVE}

Formación; Literacidad Digital Crítica; Hiperlector; Narrativas orales; Game Digital/RPG. 


\section{INTRODUÇ̧̃̃o}

Este artigo apresenta proposição inicial de um projeto de pesquisa ${ }^{3}$ em desenvolvimento no Mestrado Profissional em Educação e Diversidade - MPED e discute sobre a formação do hiperleitor na perspectiva do Letramento Digital Crítico, a partir de textos potencializados pelas Tecnologias da Informação e Comunicação (TIC). Tem como foco o trabalho com a retextualização de narrativas orais (MARCUSCHI, 2010) de moradores do campo do município de Monte Santo-BA, transformando-as em narrativas hipertextuais (LÉVY, 1993; XAVIER, 2009) veiculadas pelo Role Play Game Digital (RPG).

Consideramos que essas narrativas hipertextuais podem promover uma experiência de intercâmbio entre comunidade e alunos por meio do exercício da "escuta" de memórias, oportunizando sua propagação por meio do diálogo entre o texto digital e o impresso. 0 trabalho pretende dar visibilidade a essas narrativas orais que resguardam saberes dos povos dessas comunidades.

Constitui-se um desafio considerar a formação de um leitor que dialogue com a diversidade de textos presentes na era atual e elaborar meios que oportunizem aos alunos empoderar-se em relação a práticas leitoras; mas, urge daí e justifica-se, a discussão sobre os efeitos que a leitura dessas narrativas orais podem apresentar para a formação do estudante, que poderá vivenciar a ampliação de práticas multiletradas contextualizadas na sala de aula.

Nessa perspectiva, esta pesquisa enfatiza as narrativas orais pouco utilizadas como objeto de ensino de Língua Portuguesa e propõe seu compartilhamento em espaços digitais, por meio das narrativas hipertextuais. Busca potencializar o letramento digital, de forma crítica, dos jovens multiletrados do campo, sujeitos que estão envolvidos nesta pesquisa, que dialogam no cotidiano com a diversidade de textos presentes nos ambientes multissemióticos e utilizam as TIC no agenciamento de suas aprendizagens fora do ambiente escolar.

Não obstante, observa-se que esses sujeitos vivenciam na escola ações didáticas desenvolvidas para sua formação, que tencionam para uma prática que privilegia textos impressos em detrimento das modalidades oral e digital. Geralmente, desconsideram-se gêneros discursivos pertencentes a modalidades que circulam nas esferas digitais, não atendendo, de forma suficiente, às demandas atuais relacionadas aos diferentes letramentos (KLEIMAN, 2007).

Trata-se de uma dicotomia evidenciada no cotidiano escolar: o trabalho com o texto na escola não tem satisfatoriamente formado hiperleitores e a realidade sociocultural do aluno, muitas vezes, não é contemplada na práxis docente. Geralmente, notamos que a formação do leitor está centrada em práticas de escrita e de leitura utilizadas como pretextos para atividades metalinguísticas, suprimindo letramentos cotidianos dos sujeitos.

Sustentada nessa prática de ensino, a escola tem como tendência privilegiar o modelo autônomo de letramento, apresentando a escrita desvinculada de contextos de uso e não priorizando o trabalho da leitura no âmbito da formação do sujeito crítico, preparando-o a partir de um único letramento.

30 projeto de pesquisa foi aprovado pelo Conselho de Ética em Pesquisa (CEP) da Universidade do Estado da Bahia pelo parecer consubstanciado CAAE: 35130920.2.0000.0057. 
Street (2014), propondo um modelo ideológico, "vê as práticas de escrita como associadas ao contexto social, cultural e estrutura de poder da sociedade” (ANECLETO, 2014, p. 49).

À vista disso, a partir do modelo ideológico (STREET, 2014) como contraponto a práticas de leitura e de escrita apenas calcadas no modelo autônomo, espera-se a promoção de práticas letradas associadas ao contexto sociocultural do aluno, de maneira que é a partir da carga cultural dos sujeitos que a apropriação dessas ações se constitui como base para a produção e a socialização do conhecimento. Portanto, o modelo ideológico propõe o letramento tomado como prática social e não apenas como produto técnico, sendo o contexto determinante na maneira como os indivíduos lidam com a escrita e pressupõe que não deve haver dicotomização entre a comunicação oral e escrita.

\section{2 [MULTIJLETRAMENTOLS) E ENSINO DE LÍNGUA PORTUGUESA}

De acordo com Kleiman (1995, p. 19), “podemos definir hoje letramento como um conjunto de práticas sociais que usam a escrita, enquanto sistema simbólico e enquanto tecnologia, em contextos específicos". Os Novos estudos do Letramento (NEL) apresentam uma nova tradição em considerar a natureza do conceito; focaliza o fenômeno não apenas como um conjunto de competências, mas como implicado nas práticas sociais, propondo que se transcenda o trabalho com "as letras" no espaço escolar para uma concepção que toma a escrita no âmbito das práticas socioculturais historicamente situadas.

Segundo Rojo (2009, p. 98), o termo Letramento "busca recobrir os usos e práticas sociais de linguagem sejam eles valorizados ou não, locais ou globais, recobrindo contextos sociais". E, ainda nesse sentido, Street (2014, p. 121) nos questiona: “[...] se, como argumentamos, existem múltiplos letramentos, como foi que uma variedade particular veio a ser considerada como único letramento?"

Destarte, é preciso atentar-nos para as reflexões acerca dos Letramentos advindas das contribuições dos NEL. Letramentos implicam as maneiras pelas quais as diferentes culturas concebem a escrita, o que reflete nas relações sociais. Dessa forma, nessa perspectiva, práticas de leitura e de escrita apresentam-se de forma plural, diversa quanto à constituição textual, às semioses e modalidades de linguagem que permeiam os textos. Por essa abordagem teórico-metodológica, base epistemológica para esta pesquisa, afirmamos que o papel da escola, como uma das principais agências formais de letramento, é possibilitar que os alunos participem de diversos eventos de letramento, a partir de práticas multiletradas que compõem seus contextos sociais.

Os eventos de letramento podem ser entendidos como as ocasiões em que, nas interações humanas, a língua escrita está presente e exerce algum papel sociocomunicativo. Levam-se em conta valores, crenças, discursos, atitudes, construções sociais dos participantes em relação aos textos. Esses eventos ampliam-se de acordo com práticas de letramento em que os sujeitos participam. Práticas de letramento correspondem à forma como os diferentes entornos socioculturais lidam com os usos da escrita, o que inclui valores que atribuem a determinados usos, recorrência ou ausência de um uso ou outro investimento maior ou menor de tempo e de recursos em usos específicos da escrita. 
Nesse sentido, é possível visualizar nas aulas de linguagem que existem práticas de letramento que se tornam dominantes, geralmente centradas em aspectos da cultura escolar. À vista disso, neste estudo, parte-se da perspectiva de um ensino que tenha como base o letramento cultural (HIRSCH, 1987), que problematize práticas de leitura presentes nas salas de aula para que atendam à diversidade de linguagens e de modalidades textuais que fazem parte da cultura impressa e digital, de forma multiletrada.

Na esteira desse debate, Rojo (2012) chama a atenção para a incorporação dos multiletramentos no cotidiano. A autora pontua que o termo multi refere-se à multiplicidade de práticas de leitura e de escrita, envolve a diversidade de linguagens, semioses e mídias responsáveis pela produção de textos multimodais e pela pluralidade cultural trazida pelos leitores. É importante considerar um ensino gerador de produção cultural que corrobore para vincular a educação à realidade do sujeito a partir de tarefas escolares que sejam sempre significativas para o aluno.

Frente à grande mobilidade e à dinamicidade do mundo moderno, com a existência de fenômenos como a globalização e a presença das TIC, difundiu-se o acesso ao conhecimento, à troca de informações e de experiências, ampliando possibilidades de interação na cultura digital. Também, evidencia-se que, nessa sociedade constituída de ambiente multimodal e multissemiótico, não é mais possível uma formação embasada em propostas pedagógicas limitadas a atender exigências apenas escolares; mas urge que potencialize leitores para que atendam às demandas desse novo contexto de múltiplas linguagens.

Assim, emerge a formação desse novo leitor - o hiperleitor - e tal formação constitui-se como elemento que o torna pleno de autonomia, apto a posicionar-se diante do mundo e da palavra. Esse hiperleitor é calcado no leitor ubíquo e imersivo (SANTAELLA, 2004), capaz de navegar por diferentes linguagens, que é implicado no mundo virtual e se adapta aos novos suportes projetados pelo ambiente multissemiótico de leitura e de escrita. É o leitor hábil no manejo das tecnologias; realiza leitura fragmentada no ciberespaço, transitando pelas diversas possibilidades de navegação de links e no "nós e conexões" e "arquiteturas líquidas" (SANTAELLA, 2004).

Nesse cenário digital, a leitura não é mais linear e fechada como no texto impresso, pois agora possibilita diferentes trajetórias multilineares e dinâmicas, condicionadas pela navegação e pela convergência de mídias. 0 perfil desse novo leitor, que interage com a informação disseminada pelas mídias digitais, demanda criticidade, rapidez e seletividade de informação: “[...] um leitor em estado de prontidão, conectando-se entre nós e nexos, num roteiro multilinear, multissequencial e labiríntico que ele próprio ajudou a construir ao interagir com os nós [...]” (SANTAELLA, 2004, p. 33).

Assim, o perfil do aluno enquanto sujeito de criticidade ganha espaço. Monte Mór (2015) apresenta uma noção de crítica, utilizando o termo critique associada ao Letramento, conferindo-lhe um caráter crítico.

No letramento crítico, a noção de crítica se refere à definição de critique e possivelmente a de crítica ideológica, considerando-se que a crítica remete a uma vivência social, a uma reorganização do conhecimento e a uma autoria nos sentidos construídos pelo leitor, espectador, interlocutor, pessoa, enfim, cidadão. (MONTE MÓR, 2015, p. 43).

A autora acredita no desenvolvimento da percepção crítica, que está imbricada na teoria dos Letramentos (letramento crítico, novos letramentos e multiletramentos) e chama a atenção para a ne- 
cessidade de considerá-lo no ambiente escolar. Portando, o chamado Letramento Crítico compreende a consciência crítica como uma atividade a ser desenvolvida nas práticas sociais. Monte Mór (2015, p. 39) pondera que "nos recentes estudos sobre letramento, a questão da crítica se renova ao ser abordada por uma perspectiva que se relaciona à linguagem como uma prática social”.

0 trabalho que dá visibilidade a essa percepção associada às práticas letradas no trato com o texto transcende sua função mecânica; ademais, aliado às práticas no ciberespaço, promove a descoberta do aluno enquanto sujeito histórico que ocupa espaço e tempo na construção do empoderamento textual-discursivo. É necessário reconhecer a relevância das estratégias utilizadas nos ambientes virtuais que fomentam práticas letradas críticas, visto que são repletos de recursos semióticos das redes e conexões e promovem a informação, a pesquisa, a socialização, o contexto e as interações entre os alunos.

Dessa forma, a partir de referenciais teóricos que balizam as TIC e das diferentes inquietações que motivaram esta pesquisa, esperamos o rompimento do processo de letramentos apenas verticalizados, que, muitas vezes, promovem relativo apagamento dos sujeitos hiperleitores, desconsiderando suas características. Com esta pesquisa, propomos que o educador também acolha o potencial dos ambientes informacionais que surgem com as novas mídias e tecnologias, dando ênfase à questão da hiperleitura.

\section{AMPLIANDO PRÁTICAS COM VISTAS A UMA EDUCAÇÃO ESCOLAR PLURAL: DIÁLOGO ENTRE O TEXTO DIGITAL E O IMPRESSO}

De forma suficiente, considerando que a educação escolar não tem atendido às demandas atuais no sentido de instigar os jovens hiperleitores do campo ao engajamento de situações didáticas, intuímos que práticas ligadas à cultura digital e ao uso de novos gêneros discursivos se tornem ações significativas no espaço escolar. Os gêneros discursivos da esfera digital permeiam o cotidiano dos alunos, suscitando novas práticas formativas. Dessa forma, constitui-se um desafio considerar a formação do leitor que dialogue com a diversidade de textos presentes no ciberespaço, a partir das diversas mídias digitais.

Nesse sentido, torna-se importante a elaboração de estratégias que oportunizem aos alunos empoderar-se em relação a práticas leitoras, constituindo-se a partir da identidade de jovens do campo que navegam pelas infovias do ciberespaço. Daí urge a importância do trabalho com diferentes práticas e usos de suportes de leitura que possam garantir o diálogo entre texto impresso e digital na formação do hiperleitor. Nesse contexto, refletimos acerca da intermediação que está sendo empregada entre o educando e suas leituras, no sentido de a escola apresentar estratégias que valorizem "sujeitos de leitura" e de autonomia, contemplando também a voz do sujeito hiperleitor do campo.

Somamos, ainda, a reflexão acerca do rompimento de fronteiras entre quem lê e quem escreve, haja vista as possibilidades oferecidas pelo ambiente digital para a construção de hipertextos que viabilizem a coautoria hibridizando autor/leitor. O hipertexto “[...] é um conjunto de nós ligados por conexões. Os nós podem ser palavras, páginas, imagens, gráficos ou partes de gráficos, sequências sonoras, documentos complexos que podem eles mesmos ser hipertextos" (LÉVY, 1993, p. 33). Dessa forma, as intervenções do sujeito hiperleitor estão fortemente presentes na materialização dos hipertextos. 
O hipertexto, então,

[...] permite uso, manuseios e intervenções do leitor infinitamente mais numerosos e mais livres do que qualquer uma das formas antigas do livro. [...] O leitor não é mais constrangido a intervir na margem, no sentido literal ou no sentido figurado. Ele pode intervir no coração, no centro. (CHARTIER, 1998, p. 77)

Esse novo sujeito/leitor escolhe inumeráveis caminhos entre os emaranhados elos do hipertexto de forma autônoma e imbuída de criticidade. Nesse sentido, a hiperleitura supõe a emancipação e a autonomia na trilha de caminhos que transcendem o "leitor autorizado" para ser um leitor mais produtivo de um novo perfil cognitivo - o leitor imersivo (SANTAELLA, 2004).

O Letramento Digital Crítico chancela um compromisso social, pois propicia a autoria e a coautoria do hiperleitor na construção do conhecimento (TAKAKI, 2017). Nessa perspectiva, neste artigo, apresentamos uma proposta de outra prática pedagógica que contemple habilidades e competências de leitura que permeiam o universo do aluno hiperleitor, mobilizando-o para a ampliação de múltiplos letramentos, dentre eles o Letramento Digital Crítico (TAKAKI, 2017).

\section{NAS TRILHAS DAS NARRATIVAS ORAIS E HIPERTEXTUAIS}

No contexto da cultura digital, a partir da inserção das práticas multiletradas com ênfase na retextualização das narrativas orais, o hiperleitor é acionado a desenvolver outras formas de pensar e agir sobre o texto, de modo colaborativo. Na busca por proporcionar novas experiências textuais, estaremos, decerto, valorizando a multiplicidade de culturas e os modos de uso da linguagem. Acrescentemos, também, o trabalho para a formação do sujeito enquanto hiperleitor crítico-emancipado, pautado numa metodologia que contemple suas vivências.

Na era da navegação pelas infovias no ciberespaço, em que surge essa geração de hiperleitores, há infinitas possibilidades pedagógicas capazes de contribuir com o ato de ler. Porém, nem sempre são materializadas em uma pedagogia da hiperleitura em sala de aula. As TIC vêm trazendo transformações na produção de conhecimentos, valores e saberes desses sujeitos, potencializando a atividade da leitura multiletrada on-line.

0 estímulo à valorização do contexto do aluno, como as narrativas orais, pode constituir-se como ponto de partida para o trabalho de formação desse hiperleitor. Em algumas comunidades rurais, o hábito de contar histórias é presente como prática importante para a valorização da cultura do povo e contribui na constituição de aspectos da tradição da própria localidade; se não preservadas, corre-se o risco de um esvaziamento das memórias, comprometendo o reconhecimento da sua identidade e promovendo um silenciamento dessas vozes.

Como expressa Michael Pollak (1992, p. 204), “[...] a memória tem um caráter primordial para elevação de uma nação e de um grupo étnico, pois aporta elementos para sua transformação e é 
um elemento constituinte do sentimento de identidade". A maioria dos alunos das pequenas cidades é oriunda de comunidades rurais e tende a perder costumes se a escola não os contextualiza. É importante o trabalho na sala de aula com esse patrimônio cultural por meio de um exercício de escuta às memórias dos anciãos, já que eles carregam em seu âmago informações que manifestam a identidade cultural da localidade.

Assim, a prática de contar histórias oferece meios de transmitir a experiência dos outros àqueles que estão distantes de nós no espaço e no tempo e contribui para formar leitores. Conta-se "para fazer da diversidade cultural um fato; valorizar as etnias; manter a história viva; para encantar e sensibilizar o ouvinte; resgatar significados para a nossa existência e reativar o sagrado" (BUSSATO, 2003, p. 54). Vê-se que a escola dispõe de um saber importante a ser explorado.

O trabalho pedagógico com a leitura pensado junto aos sujeitos do campo, que valoriza e contempla a cultura local, pode contribuir para que os sujeitos inseridos nessa geração da interatividade não fiquem indiferentes à sua cultura local. Esse trabalho, aliado às TIC, tende a potencializar espaço para acolher a socialização dessas histórias que funcionam como testemunhas vivas de gerações e de modos de vida.

A pesquisa aqui apresentada propõe como objeto de estudo, a retextualização de práticas textuais orais para narrativas hipertextuais, a partir do game RPG digital. Nessa perspectiva, os sujeitos da pesquisa farão a coleta de narrativas orais do município, utilizando artefatos digitais para as retextualizar e, na sequência, as transformarão em hipertextos por meio do RPG digital.

Marcuschi (2010) caracteriza a retextualização enquanto processos e operações que ocorrem na passagem de um gênero textual-discursivo de uma modalidade da língua para outra. Pretende-se, aqui, aliar a oralidade à escrita na tela, oportunizando o desenvolvimento de novas competências que são inerentes a cada modalidade, como também valorizar as experiências socioculturais expressas nessas narrativas, vislumbrando as TIC relacionadas à interação, colaboração, representação e expressão de identidades dos hiperleitores.

As experiências advindas das narrativas orais são marcadas por muitas vozes e devem ser consideradas na integração entre a cultura local e a sua ampliação para a global. Sob essa égide, indaga-se: como o trabalho com RPG digital pode contribuir para ampliar o letramento digital crítico, a partir da inserção das narrativas orais, constituídas como identidade da cultura local dos jovens multiletrados do campo, nas atividades de leitura?

Propomos a elaboração de dispositivos e discussões de práticas que tragam em seu bojo ações escolares contextualizadas pela materialidade das narrativas orais, transformadas em narrativas hipertextuais por meio do jogo digital/RPG, nesta pesquisa também considerado como gênero discursivo, com vistas à formação do hiperleitor.

$\mathrm{O}$ uso de artefatos digitais dará suporte à construção do designer do game RPG digital. Pesquisadores, desde a década de 1990, sugerem o RPG como dispositivo textual importante para a área educacional, visto que se configura como uma atividade que desenvolve diferentes competências de leitura/ hiperleitura. Segundo Ricon (2002, p. 15), o Roleplaying Game "é uma brincadeira de contar histórias coletivamente". RPG é uma sigla em inglês que pode ser traduzida como "Jogo de Interpretação de Personagens"; contribui para a aprendizagem, visto que tem como características "a socialização, colaboração, criatividade, interatividade, interdisciplinaridade” (GRANDO; TAROUCO, 2008, p. 8). 
Nesse jogo, tradicionalmente, um grupo composto por narrador e personagens se reúne para representar uma história. Existe um "narrador" que explica o desenrolar da trama e os jogadores que interpretam seus personagens. Nessa perspectiva, o jogo pode ampliar, de forma colaborativa, o processo dado à retextualização de textos orais em hipertextuais, a partir do trabalho com multissemioses (cores, movimento, desenhos, som etc.) e multimodalidades (oral, escrito, hipertextual, sonoro), práticas do gênero discursivo multiletrado RPG.

Consoante a essa proposta, temos a diversificação de práticas que ampliam o Letramento Digital Crítico e fortalecem a formação do hiperleitor, a iniciativa e o diálogo, sem desvalorizar aspectos culturais da comunidade desses alunos, a partir de uma proposta de produção colaborativa com as TIC. Ademais, para a construção da autonomia interativa do discente são necessárias atividades de leitura plurais, que ampliem estratégias de interação textual, pautadas em uma educação contextualizada.

\section{MAPEANDO FORMAS DE TRAVESSIA}

A escolha teórico-metodológica da pesquisa em proposição sustenta-se na abordagem qualitativa, visto que se configura como uma atividade da ciência que visa à construção da realidade e que, segundo Minayo (2001, p. 22), "trabalha com o universo dos significados, motivos, aspirações, crenças, valores e atitudes, o que corresponde a um espaço mais profundo das relações, dos processos e dos fenômenos [...]". Com base nos procedimentos técnicos utilizados, a natureza da pesquisa compreende a pesquisa participante, sendo que a comunidade (nesta pesquisa alunos da escola locus) participa da análise de sua própria realidade (GROSSI, 1981).

O processo investigativo partirá do questionário on-line pelo formulário Google e do RPG digital. Para a interpretação das informações a serem construídas, optamos como método a análise de conteúdo (BARDIN, 1977). A vivência do jogo dar-se-á por meio das narrativas hipertextuais, utilizando aplicativo de mensagem para essa construção.

Inicialmente, como dispositivos de pesquisa, pretendemos elaborar oficina sobre RPG digital. As oficinas serão realizadas em espaço-tempo de sala de aula, durante o componente disciplinar Língua Portuguesa, ministrado pela professora-pesquisadora na escola locus. Escolhemos como processo formativo as oficinas, porque elas potencializarão as práticas sociais dos discentes-colaboradores por ter como base a interação, a participação, a partilha de saberes, a criatividade e o diálogo em favor do trabalho coletivo, oportunizando, assim, uma perspectiva colaborativa no processo formativo.

Como objeto de estudo nas oficinas, partiremos do dispositivo RPG. Destacamos que, sobre seu estudo, pretendemos, após o mapeamento inicial dos conhecimentos prévios dos alunos sobre o jogo, ratificar e/ou apresentar sobre a sua composição, seus elementos e definição; contexto das narrativas vinculadas ao jogo quanto aos seus aspectos históricos, sociais, ambientais, culturais; aplicação dessas narrativas para a modelagem do jogo e da organização da mídia digital, entre outros conteúdos que surgirão no campo empírico.

Como meio para a organização das atividades dessas oficinas serão elaboradas sequências didáticas, a partir das necessidades educativas dos sujeitos da pesquisa. Para a construção desse arte- 
fato pedagógico, partiremos de algumas etapas: negociação da proposta de trabalho com os alunos; mapeamento do conhecimento prévio discente; análise, junto com os alunos, dos conteúdos a serem trabalhados; pesquisa e produção de atividades sobre a temática a ser abordada; realização da avaliação da aprendizagem (ANECLETO, 2018).

Para a catalogação das narrativas orais, objeto das atividades da SD, os alunos realizarão o trabatho de escuta desses textos em suas comunidades, arquivando-os em formato de áudio. Essas narrativas que, em outro momento serão retextualizadas do oral para o digital, constituirão o ponto de partida para a construção do jogo RPG.

As práticas de letramento e de multiletramentos vivenciadas pelos sujeitos durante todo o processo de pesquisa, desde o momento da pesquisa exploratória até as práticas de retextualização das narrativas, serão problematizadas entre os participantes durante as aulas de Língua Portuguesa e por aplicativos de mensagens. No designeraqui proposto, os participantes se encontrarão, mediados pelas TIC, para vivenciar o jogo, (re)construindo uma história coletiva com base nas narrativas orais pesquisadas em suas comunidades.

A partida será delineada pela seguinte estrutura: a pessoa que irá orientar a partida entre os jogadores, denominado “mestre”, irá, previamente, agendar o horário garantindo que todos estejam on-line; ao começar o jogo, expõe as regras no grupo formado no aplicativo. 0 mestre lança a campanha (texto que descreve em linhas gerais a narrativa selecionada pelo grupo) e orienta que cada jogador indique qual personagem escolhe representar naquela partida. Escolhidos os personagens, cada jogador elabora uma ficha com suas características e a compartilha.

O mestre descreve uma situação inicial; cada jogador define livremente sua ação de acordo com as possibilidades oferecidas e comunica a atitude de seu personagem diante da proposição. Na sequência, o mestre anuncia os desdobramentos das ações que, em alguns casos, precisam ser submetidas a testes, cujos resultados se definem por números obtidos em dados. Assim, o jogo vai sendo construído, de forma coletiva, a partir das ações dos personagens, direcionando cada destino e sendo definidos os rumos do enredo, por práticas hipertextuais. Termina a partida quando o grupo considera ter desenvolvido, satisfatoriamente, a história proposta pelo mestre.

Os sujeitos colaboradores serão os discentes de uma turma de $9^{\circ}$ ano do Ensino Fundamental, do Colégio Municipal Professora Otacília Cardoso de Matos. Escolhemos essa fase de escolarização por corresponder à terminalidade desse ciclo educacional, quando se espera a consolidação de competências textuais multiletradas dos alunos.

Por fim, propomos, nesta pesquisa, a discussão sobre práticas de leitura que tragam o princípio da contextualização, a partir das narrativas orais, transformadas em narrativas hipertextuais, a partir do jogo digital RPG, com vistas à formação do hiperleitor multiletrado do campo.

\section{CONSIDERAÇÕES FINAIS}

Consideramos que o RPG apresenta uma proposta que tem por base a produção colaborativa de prática de leitura, mediada pelas TIC. Ele possibilita, por meio de sua estrutura narrativa, o envolvi-

Interfaces Científicas - Aracaju - V.10 - N.2 - p. 37 - 49 - Número Temático - 2020 
mento dos estudantes em práticas textuais, de forma divertida, reflexiva e contextualizada, favorecendo, também, a formação do hiperleitor.

O jogo, também, se apresenta como uma maneira de valorização de práticas multiletradas a partir do desenvolvimento de competências leitoras por meio da coletividade e da interação propiciadas durante as partidas. Além disso, os multiletramentos são contemplados nesse game, pois, desde a leitura instrucional das fichas de personagens, dos dados de habilidade, da representação do personagem, ao final da aventura, é indispensável o envolvimento dos sujeitos em atividades de textos multimodais.

Nesse ínterim, este artigo apresenta a importância do trabalho em sala de aula com novas articulações textuais e hipermidiáticas. Perpassou pelo diálogo entre narrativas orais e narrativas hipertextuais, a serem construídas pelos sujeitos da pesquisa por um movimento de retextualização de gêneros discursivos. Dessa forma, este trabalho enfatiza formas textuais, às vezes não contempladas no espaço escolar, mas que resguardam importância histórica e que agora podem ser calcadas num aparato tecnológico, usado como artefato para preservação cultural.

Com a construção dessas atividades, destacamos a possibilidade de ocorrer o fortalecimento da autonomia de leitura de hipertextos do discente, que se torna hiperleitor. A formação do hiperleitor constitui-se, então, como elemento que pode potencializá-lo como leitor multiletrado pela/na mídia digital. 0 trabalho de escuta e de arquivamento dessas narrativas, a serem aplicadas ao RPG digital, transcende uma função mecânica da leitura na escola. Assim, pode promover a formação desses hiperleitores como sujeitos históricos na construção de seu empoderamento textual-discursivo.

\section{REFERÊNCIAS}

ANECLETO, Úrsula Cunha. Letramento escolar e cotidiano: análise de experiências sobre práticas de letramento à luz da crítica cultural. Jundiaí: Paco Editorial, 2014.

ANECLETO, Úrsula Cunha. Sequência didática e aula de Língua Portuguesa: fomentando eventos de letramento na escola. In: PEREIRA, Áurea da Silva; CRUZ, Maria de Fátima Berenice de; PAES, Maria Neuma Mascarehas. Letramentos, identidades e formação de educadores: imagens teóricometodológicas de pesquisas sobre práticas de letramento. Campinas-SP: Mercado das Letras, 2018.

BARDIN, Laurence. Análise de conteúdo. Tradução L. de A. Rego; A. Pinheiro. Lisboa: Edições 70. (Obra original publicada em 1977).

BUSSATO, Cléo. Contar e encantar pequenos segredos da narrativa. Petrópolis: Vozes, 2003.

CHARTIER, Roger. A aventura do livro do leitor ao navegador. Tradução de Reginaldo Carnello C. de Moraes. São Paulo: Editora Unesp, 1998. 
GROSSI, Y. de S. Mina de Morro Velho: a extração do homem, uma história de experiência operária. São Paulo: Paz e Terra, 1981.

GNL - Grupo de Nova Londres. A pedagogy of multiliteracies: Designing Social futures (Cazden, Coutney; Cope, Bill; Fairclough, Norman; Gee, Jim; et al.) Havard Educational Review. Spring, 1996. p. 60-92.

HIRSCH, JR. E. D. Cultural literacy. Boston: Houghton Mifflin, 1987.

KLEIMAN, Ângela B. (org.). Os significados do letramento: uma nova perspectiva sobre a prática social da escrita. Campinas-SP: Mercado de Letras, 2006.

LÉVY, Pierre. As tecnologias da inteligência. Tradução de Carlos Irineu da Costa, Rio de Janeiro: Ed. 34, 1993. MARCUSCHI, L. A. Da fala para a escrita: atividades de retextualização. 10. ed. São Paulo: Cortez, 2010. MINAYO, Maria Cecília de Souza (org.). Pesquisa social. Teoria, método e criatividade. 18. ed. Petrópolis: Vozes, 2001.

MONTE MÓR, Walkiria. Crítica e letramentos críticos: reflexões preliminares. In: ROCHA, Claudia Hildorf; MACIEL, Ruberval Franco (org.). Língua estrangeira e formação cidadã: por entre discursos e práticas. Campinas-SP: Pontes editores, 2015.

POLLAK, Michael. Memória e identidade social. In: POLLAK, M. Estudos Históricos. São Paulo, 1992.

RICON, Luiz Eduardo. 0 resgate de “Retirantes": uma aventura de RPG pela vida de Cândido Portinari. Simpósio RPG \& Educação, São Paulo, 2002.

ROJO, Roxane H. R. Pedagogia dos multiletramentos: diversidade cultural e de linguagens na escola. In: ROJO, Roxane Helena Rodrigues; MOURA, Eduardo (org.). Multiletramentos na escola. São Paulo: Parábola Editorial, 2012.

SANTAELLA, Lúcia. Navegar no ciberespaço: o perfil cognitivo do leitor imersivo. São Paulo: Paulus, 2004.

STREET, Brian. Letramentos sociais: abordagens críticas do letramento no desenvolvimento, na etnografia e na educação. Tradução Marcos Bagno. São Paulo: Parábola editorial, 2014.

TAKAKI, N. H.; MOR, W. M. (org.). Construções de sentido e letramento digital crítico na área de línguas/linguagens. Campinas-SP: Pontes, 2017.

XAVIER, Antônio Carlos. A era do hipertexto: linguagem e tecnologia. Recife: UFPE, 2009. 
1 Mestranda no Programa de Pós-graduação em Educação e Diversidade - PPED/UNEB; Membro do Grupo de Estudo e Pesquisa em (Multi)letramentos, Educação e Tecnologias - (GEPLET/CNPq; Professora de Língua Portuguesa na Educação Básica, Monte Santo-BA.

E-mail: geisaaraujodias@gmail.com

2 Doutora em Educação pela Universidade Federal da Paraíba - UFPB; Professora no Programa de Pós-graduação em Estudos Linguísticos - PPGEL/UEFS, no Programa de Pós-graduação em Educação e Diversidade - PPED/ UNEB e no Departamento de Educação na Universidade Estadual de Feira de Santana - DEDU/UEFS, Feira de Santana-BA; Líder do Grupo de Estudo e Pesquisa em (Multi)letramentos, Educação e Tecnologias - GEPLET/CNPq.

E-mail: ucanecleto@uefs.br

\section{(2) (1) (-)}

Este artigo é licenciado na modalidade acesso abertosob a Atribuição-Compartilhalgual CC BY-SA

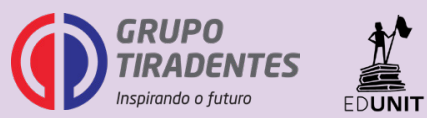

